\title{
Para que Serve uma Subjetividade? Foucault, Tempo e Corpo
}

\author{
Hélio Rebello Cardoso Jr. ${ }^{1}$
}

Universidade Estadual Paulista, Assis

\begin{abstract}
Resumo
O presente artigo procura retomar a mudança de rumo da obra de Foucault que determinou o enfoque sobre a subjetividade, sobretudo nos dois últimos volumes de História da Sexualidade. Com isso, nossa atenção volta-se para os marcos da definição de subjetividade como processo ou prática, que são a relação com o tempo e a dimensão transformacional ou criativa do corpo. Tal investigação conceitual sobre a subjetividade em Foucault procura indicar, outrossim, de que maneira a criação filosófica está relacionada ao modo de vida ou estilo de um filósofo. O pensamento derradeiro de Foucault é consistente com o estilo que ele vinha construindo no decorrer de sua obra, de modo que se discute a invectiva de que esta última fase, por razões várias, seria o lugar de um retorno do sujeito ou do homem que Foucault havia negado anteriormente. Palavras-chave: Foucault; subjetividade; subjetivação; vida.
\end{abstract}

What a subjectivity is useful for? Foucault, Time and Body

\begin{abstract}
The present article main proposition focuses on the turn made by Foucault when he takes into a new account the theme of the subjectivity, above all in the last two volumes of History of the Sexuality. Henceforth, our attention retraces the two characters of the subjectivity definition as a process or practice, it means, our relationship with the time and the creative or transformative dimension of the body. We argue, then, against the assertion that Foucault's last issue would imply the return of the subject or of the man that he had previously denied, that the last Foucault is consistent with the style that he had been building throughout his past books.

Keywords: Foucault; subjectivity; subjectivation; life.
\end{abstract}

Quando Foucault apresentou o curso $A$ bermenêutica do sujeito (Foucault, 2001b), em 1981 e 1982, cujo teor verte para os dois volumes finais de História da sexualidade (Foucault, 1984, 1985b), nota-se uma mudança em sua trajetória. A notória questão acerca do saber e do poder, que até então tinha sido a marca do pensamento foucaultiano, mais precisamente até o primeiro volume de História da Sexualidade (Foucault, 1985a), é acrescida de uma indagação a respeito das práticas pelas quais nos tornamos sujeitos. Foucault é explícito a respeito da mudança de trajetória quanto a uma genealogia da sexualidade, na medida em que se trata, então, de estudar de que maneira o indivíduo moderno podia fazer a experiência dele mesmo enquanto sujeito de uma sexualidade (Foucault, 1984, p. 11). Desta forma, somos informados de que sexualidade é um dentre os modos históricos pelos quais fazemos a experiência de constituirmo-nos enquanto sujeitos.

Justamente na fase final de sua obra, nesses dois últimos volumes de História da Sexualidade, momento criativo que é abruptamente interrompido por sua morte, Foucault volta sua atenção para o sujeito. Ora, nas fases anteriores, consensualmente denominadas arqueologia do saber genealogia do poder, acostumamonos a ver Foucault anunciar a decantada morte do homem, o que se observava tanto na erosão deste homem como sujeito e objeto do conhecimento quanto em sua produção como sujeitoindivíduo nos espaços disciplinares. No primeiro caso, temos a famosa imagem que evidenciaria o niilismo focaultiano em toda

${ }^{1}$ Endereço para correspondência: Universidade Estadual Paulista Júlio de Mesquita Filho, Faculdade de Ciências e Letras de Assis, Departamento de História, Av. Dom Antônio, 2001, 19806 173, Assis, SP. Fone: (18) 33025861; Fax: (18) 33244537. Email:herebell@hotmail.com; herebell@uel.br sua plenitude, tendo como pano de fundo a iminência da alteração das disposições históricas que estruturariam a episteme moderna em torno da invenção do homem:

se estas disposições viessem a desaparecer tal como apareceram, se, por algum acontecimento de que podemos quando muito pressentir a possibilidade ... se desvanecessem, como aconteceu, na curva do século XVIII, com o solo do pensamento clássico - então se pode apostar que o homem se desvaneceria, como, na orla do mar, um rosto de areia. (Foucault, 1981,p. 404)

Ora, em todo caso, estaria Foucault se desmentindo ou se retratando, como supôs Dosse (1994), ao tematizar o sujeito, o homem, que ele havia tão veementemente negado?

Deleuze nos auxilia a responder a essa pergunta dirigida a Foucault quando afirma com certa indignação que nunca o perdoaram por haver anunciado a morte do homem (Deleuze, 1986, p. 11). Com efeito, para os críticos mais complacentes, o suposto retorno ao sujeito, a partir dos dois volumes de História da sexualidade referidos, soaria como uma espécie de retratação tardia, já que enfim um certo lenitivo aliviaria a todos aqueles que, admiradores de primeira hora por se identificarem com as posições libertárias de Foucault, sentiam-se ao mesmo tempo incomodados com o rescaldo de seus livros e declarações, na medida em que estes amofinavam a crença nos Direitos Universais do Homem. Ou, para os críticos mais acerbos, a emergência do tema do sujeito teria sido a oportunidade de surpreender certa incoerência na obra de Foucault, incoerência esta que facultaria uma espécie de superioridade moral a todos aqueles que, críticos antigos, já vinham denunciando a insolvência ou fatuidade do pensamento foucaultiano, como se afinal chegasse o momento de retratação que estes críticos vaticinavam desde sempre. Quanto a essas invectivas, Deleuze mais 
uma vez vem em nosso auxilio, afastando qualquer dúvida ao declarar de modo peremptório:

hoje, novos imbecis, ou os mesmos reencarnados, se admiram porque Foucault participava das lutas políticas, ele que disse a morte do homem. Contra Foucault, eles invocam uma consciência universal e eterna dos direitos do homem que deverá ficar ao abrigo de toda análise. Não é a primeira vez que o recurso ao eterno é a máscara de um pensamento débil demais... É verdade que Foucault nunca deu grande importância ao universal e ao eterno: são somente efeitos massivos que vêm de certas repartiçös de singularidades, em tal formação histórica, e sob tal processo de formalizaçãa. (Deleuze, 1986, p. 96)

A partir daí, como entender que o sujeito se constitua bistoricamente?

Como bem assinala Deleuze (1986, p. 109), o interesse de Foucault pelo sujeito não envolve apenas uma mudança temática, mas implica uma investigação que abre um novo domínio ontológico (uma ontologia histórica), o que poderia ser percebido de modo cabal pela extensão do balizamento cronológico das pesquisas foucaultianas. De fato, a nova investida de Foucault, ao invés do tratamento secular - dois ou três séculos - que demarcava as epistemes do saber ou os dispositivos de poder em livros anteriores, recua até à Grécia clássica. Isto porque Foucault encontra nos processos que constituem a subjetividade uma vigência milenar que envolve as formações discursivas da episteme moderna e os dispositivos de poder da sociedade na qual estamos ainda imersos, como se em nosso tempo repercutisse uma história muito mais longa: a história dos processos pelos quais nos tornamos sujeitos.

Os modos pelos quais nos tornamos sujeitos, os modos de subjetivasão, aparecem e se desenvolvem historicamente como práticas de si que, embora vigorem dentro de práticas discursivas (saberes) e práticas de poder que testemunham pela descontinuidade de suas formas históricas (Foucault, 1984, p. 23), correspondem a quatro grandes focos de problematizaçōes, a saber, natureza do ato sexual, fidelidade monogâmica, relações bomossexuais, castidade (p. 17), as quais atravessam as pretensas oposições entre a filosofia pagã, a ética cristã e a moral das sociedades européias modernas (p. 18). Tais problematizações em torno do sujeito indicam, conforme Foucault, que de certa forma, a austeridade sexual, que se encontra nos primeiros filósofos de nossa era, se enraiza na tradição antiga, pelo menos na medida em que ela anuncia uma moral futura (Foucault, 1985a, 233).

A subjetividade, o sujeito, para Foucault, envolve um processo de subjetivação, visto que, segundo suas próprias, não existe constituição do sujeito moral sem modos de subjetivação (Foucault, 1984, p. 28), ou seja, toda experiência que concretiza uma subjetividade envolve modos historicamente peculiares de se fazer a experiência do si (subjetivação). Toda subjetividade expressa algo de impessoal porque supõe processos de subjetivação onde se dá a repartição de singularidades de que fala Deleuze, como vimos acima. Assim, para valermo-nos da precisa terminologia deleuzeana, a subjetividade é um efeito massivo que provém de um processo singular. Os saberes e os poderes de todos os tempos procuram domar os processos de subjetivação, mas estes lhes escapam perfazendo uma história da resistência relativa à vida, pois o ponto mais intenso das vidas, onde se concentra sua energia, fica exatamente ali onde elas se chocam com o poder, se debatem com ele, tentam utilizar suas forças e escapar de sua armadilhas (Foucault, 1977, citado em Deleuze, 1986, p. 101).

$\mathrm{Em} A$ vontade de saber, Foucault descobrira esses pontos de resistência à rede do poder, mas ele precisava responder a partir de onde se formam essas resistências difusas, na maioria das vezes imperceptíveis (Foucault, 1985a). Tal indagação tornava-se necessária a partir de uma constatação: se as subjetividades oferecem resistência, se elas estão envolvidas por processos de subjetivação que vão além da forma subjetiva, então o sujeito dispõe de uma mutabilidade ou plasticidade que the confere uma dimensão temporal ou transformacional. Tal problematização, ou seja, a procura de uma instância positiva de subjetivação, que não apareça meramente como lugar de resistência aos saberes e poderes, leva Foucault aos dois volumes seguintes de História da Sexualidade. Como declara, ao refletir sobre o desafio lançado por estes livros, essa genealogia me afastava muito de mеи projeto primitivo (Foucault, 1984, p. 11), pois esse novo domínio de análise colocava-se como ponto de interseção (p. 16) entre os dois campos de seus objetos anteriores, quais sejam, a arqueologia do saber e a genealogia do poder. Esta interseção, onde Foucault delimita o novo campo de pesquisas, pode ser definida de maneira apropriada como estando organizada em torno da relação da subjetividade com a história, pois é a respeito dessa relação que podemos observá-lo propor o que poderia chamar uma história da ética e da ascética, entendida como bistória das formas de subjetivacão moral e das práticas de si destinadas a assegurála (Foucault, 1984, p. 29).

Desse modo, e para fixar os termos postos em jogo, digamos que o problema da subjetividade em Foucault pode ser equacionado de maneira fiel pelas seguintes fórmulas: toda subjetividade é uma forma, mas essa forma é simultaneamente desfeita por processos subjetivação; enquanto a forma-sujeito é captada pelos saberes e poderes, a subjetivação é um excesso pelo qual a subjetividade mantém uma reserva de resistência ou de fuga à captação de sua forma. Mas, temos de responder ainda, para engrenar as idéias foucaultianas a respeito da subjetividade: o que é esse excesso com relação à subjetividade, ou seja, de que modo processo de subjetivação e subjetividade estão envolvidos entre si?

É esta a questão que nos compromete no presente artigo. Desenvolveremos as noções de subjetividade e de subjetivação como modo de indicar seus principais componentes e, ao mesmo tempo, como uma postura crítica, não exatamente contra os detratores de Foucault, mas como uma certa via para esclarecer e tornar acessível a posição de todos aqueles que, como Deleuze, celebram o fato de que a obra de Foucault tem uma beleza que ela parece recusar por aplicar-se aos aflitivos estudos dos escaninhos lábeis do discurso ou dos rituais meticulosos do poder. É preciso saber de que modo os leitores dessa obra feita das infâmias dos saberes e dos becos-semsaída dos poderes, estranhamente, acabam por sentir-se mais inteligentes e mais alegres, ao seguirem esses livros que têm o brilho de uma manhã de festa (Deleuze, 1986, p. 11).

pensar contém um modo de vida: subjetividade como expressão do tempo e do corpo; ataques de malquerença contra Foucault

A respeito da subjetividade em Foucault, vamos lidar com uma proposição bem simples, a saber: o conceito de subjetividade 
de Foucault, além de sua alçada teórica, contém uma perspectiva pragmática, pois envolve uma postura diante da vida, vale dizer, o conceito de subjetividade envolve um modo de vida. Passemos a uma definição nesses termos.

O problema da subjetividade em Foucault tem sido um tema muito debatido e é por isso extremamente profícuo. Mas também é um assunto bastante polêmico para os estudiosos de sua obra. Justamente, o tema da subjetividade em Foucault é polêmico pois ele comunica de maneira mais incisiva um modo de vida. Foucault sempre foi consciente e colocou em primeiro plano a relação da filosofia com a vida, entendendo tal relação como a construção de modos de viver, pois que

a filosofia é o movimento pelo qual nos libertamos - com esforços, hesitações, sonhos e ilusões - daquilo que passa por verdadeiro, a fim de buscar outras regras do jogo. A filosofia é o deslocamento e a transformação das molduras de pensamento, a modificação dos valores estabelecidos, e todo o trabalho que se faz para pensar diversamente, para fazer diversamente, para tornar-se diferente do que se é. (Foucault, 1994, p. 143, grifo nosso)

Mas como definir esse modo de vida que compreende, mesmo para um filósofo, um esforço em busca da diferenciação como trabalho próprio de uma existência?

Ora, em poucas palavras, o que o modo de vida presente na obra foucaultiana exige de nós, o que ele comunica de modo peremptório, é uma mudança em nossa relação com o tempo, a respeito da qual Foucault se manifestou nos momentos-chave em que definia os parâmetros de sua pesquisa com relação à história, principalmente, em dois momentos que convém destacarmos. Em primeiro lugar, nas primeiras páginas de Arqueologia do Saber, onde define que tipo de tratamento dá aos documentos históricos e, portanto, quais os aspectos que diferenciam sua obra com relação à historiografia contemporânea (Foucault, 2000). E, em segundo lugar, no texto Nietzsche, a genealogia e a história, onde Foucault resume os princípios que deve seguir um historiador inspirado em uma genealogia desenvolvida a partir das idéias de Nietzsche a respeito do tempo (Foucault, 1982).

Se articularmos a discussão sobre a temporalidade histórica presente no percurso foucaultiano com o argumento que estamos desenvolvendo, pode-se afirmar, com certa convicção, que uma subjetividade é a expressão do que em nós, em nosso núcleo de subjetividade, se relaciona com as coisas, com o mundo, por isso envolve uma relação com o tempo. Em função desse aspecto vital, é que podemos definir de forma apropriada o problema da subjetividade em Foucault. Dizer que a subjetividade articulase com o tempo é, sem dúvida, uma maneira de abandonar a idéia de uma subjetividade imóvel em sua fixidez, como o ego cartesiano ou a idéia de uma subjetividade vinculada a um inconsciente onde a temporalidade está articulada a uma estrutura pulsional mais ou menos invariante, como supunha Freud.

Além disso, o elo entre subjetividade e tempo, de modo mais radical, é uma forma de dizer que o sujeito é corpo, que a subjetividade é algo que acontece num corpo e dele não se desvincula. De fato, se a subjetividade é, como definimos acima, uma expressão de nossa relação com as coisas, através da história, então, o modo mais imediato pelo qual essa relação se expressa é o corpo, entendido não apenas como corpo orgânico, mas também como o corpo construído pelas relações com as coisas que encontra durante sua existência. Quando dizemos de modo um tanto cru que o corpo é um corpo das relações isso significa que o corpo envolve, então, o encontro com as coisas, ficando subentendido que uma coisa pode ser um outro corpo, orgânico ou inorgânico, uma idéia, uma imagem, etc.

Foucault, no entanto, não nos deixou desamparados quanto à suposta relação da subjetividade com o tempo e com o corpo, visto que ele procurou demonstrar rigorosamente que essa relação descrevia uma história cujo conteúdo seria uma estética da existência. Elemento este que Foucault tão bem descreveu através dos critérios de diferenciação das práticas de si relativos à determinação da substância ética, aos modos de sujeição, à elaboração do trabalho ético e à teleologia do sujeito moral (Foucault, 1984, p. 28, p. 31)?

Com isso, já temos que a subjetividade segundo Foucault tem a ver com o tempo e com o corpo. E justamente nisso reside seu potencial de polêmica e mesmo de dificuldade de abordagem. Foucault esvazia a noção de subjetividade de seus conteúdos corriqueiros e a preenche com outros, inovadores.

Os ataques de malquerença contra Foucault são notáveis e reiterados, e por isso são testemunhos do modo de vida contido em seu conceito de subjetividade e da novidade que este porta. De acordo com a crítica detratora, o fato de a última fase da obra de Foucault deter-se no problema da subjetividade testemunha sua retratação. Ora, perguntam eles, os arautos da má consciência, por que Foucault teria retornado ao tema da subjetividade se ele havia negado a existência do sujeito em seus livros anteriores (seja do sujeito epistêmico que seria um efeito discursivo; seja do sujeito psíquico, que seria produto de um dispositivo de poder)?

Tal pergunta, aparentemente plana, apresenta uma espécie de simples petição de princípio. Na verdade, contudo, ela oculta dois sentidos sub-reptícios, que são, aliás, seus verdadeiros móveis. Em primeiro lugar, essa pergunta denuncia uma profunda incoerência na obra de Foucault, e o faz com a superioridade moral de quem goza com o suposto erro alheio. Em segundo lugar, essa pergunta rastreia, nos textos finais da vida de Foucault, uma certa angústia proveniente de seu modo de ser, de estar doente de uma certa peste gay. Ora, então o suposto retorno à subjetividade em Foucault conteria mais do que uma simples incoerência quanto à continuidade de sua obra, pois esse retorno anunciaria, no fim das contas, uma dialética mais sutil, ou seja, a insinuação de uma culpa que não pode ser negada diante da morte iminente. O Vol. II de História da sexualidade, segundo Dosse:

remete ... ao não dito do indivíduo Foucault, à sua busca desesperada e urgente de uma ética, de uma ascese espiritual compensatória de um desprendimento próximo de seu corpo, de uma libertação da culpabilidade mortífera que o habita, e de uma reconciliação final consigo mesmo. Decididamente o sujeito está de volta. (Dosse, 1994, p. 389; grifo nosso) 
Foucault sempre reivindicou uma nova compleição para a crítica, uma crítica não baseada em má-fé, já que, afirmava ele, num misto a um tempo acerbo e brando,

é incrível quanto as pessoas gostam de julgar. Julga-se em todo lugar, continuamente. Provavelmente, para a humanidade, é uma das coisas mais simples a fazer ... Não posso deixar de pensar em uma crítica que não procure criticar, mas fazer existir uma obra, uma frase, uma idéia; acenderia fogos, olharia a grama crescer, escutaria o vento e imediatamente tomaria a espuma do mar para a dispersar. Reproduziria, ao invés de juízos, sinais de vida; invocá-los-ia, arrancá-los-ia do seu sono. (Foucault, 1994, p. 138)

Então, perguntamos, como livrar Foucault do anátema - para utilizar um termo teológico - que lhe lança o crítico acima transcrito, ou como livrar Foucault desse mau-olhado, para utilizar um termo mais coloquial e portanto mais eloqüente?

Ora, temos de afirmar a coerência não-sistemática em sua obra, posto que o tema da subjetividade renova e repõe o problema da relação da existência com o tempo, de modo que, nessa última fase da obra foucaultiana, tal problema será tratado sob o ponto de vista de seus modos históricos. Temos, igualmente, de observar essa coerência no sentido da continuidade do traço de anticonformismo presente na obra de Foucault, o qual provém das fases anteriores, e é reeditado a partir da idéia de que existe uma ligação extrema entre o corpo, a subjetividade e o tempo. A ligação da subjetividade com o tempo e o corpo é que a envolve em um processo de subjetivação, como afirmávamos anteriormente, visto ser o corpo o elemento que se inclui na heterogeneidade de elementos cuja relação se faz e se desfaz com o tempo.

\section{Subjetividade e tempo}

Podemos começar com Heráclito para recordarmos uma bela imagem. O tempo é como um rio nos mesmos rios entramos e não entramos, somos e não somos, em rio não se entra duas vezes no mesmo (Heráclito, citado em Diels \& Kranz, 1951, p. 161, p. 171). O paradoxo do tempo é perfeito com o rio de Heráclito: o rio é o mesmo, mas não pára de passar, portanto, o rio nunca é o mesmo, nem aqueles que se banham no rio são os mesmos, pois eles também são por ele levados.

Foucault é um filósofo que faz avançar o estudo da hidrodinâmica do rio de Heráclito, ao precisar o que acontece na relação da força da passagem do tempo com nossa subjetividade. Foucault chamou a atenção para o fato de que o modo de pensar dominante não tem sido muito afeito à água, já que na imaginação ocidental, a raz̧ão pertenceu por muito tempo à terra firme. Ilha ou continente, ela repele a água com uma obstinação maciça: ela só lhe concede sua areia (Foucault, 1999, p. 186). Aliás, lembremos com Deleuze que sempre houve em Foucault um heraclitismo mais profundo que em Heidegger (Deleuze, 1986, p. 120). Pensando o conceito de subjetividade na clave heraclitiana e foucaultiana, de que modo pode-se obter uma versão do processo de subjetivação enquanto este acontece no rio do tempo?

Um processo de subjetivação está para um rio, assim como remansos estão para a correnteza. Remansos são como riachos que correm dentro de um rio maior. Esses remansos têm suas próprias correntezas, que muitas vezes invertem o sentido da corrente maior, dobram-na fazendo pequenos turbilhões que descrevem um certo trajeto dentro do rio, mais próximos de suas margens, até se desfazerem. Podemos dizer que esses remansos são excessos do rio, pois são remoinhos que se formam em função da corrente principal. Mas eles são igualmente recessos do rio, isto é, os remansos da subjetivação funcionam como portas pelas quais novas águas entram ou são perdidas para o rio maior. A ligação da subjetividade com o tempo e o corpo é que a envolve em um processo de subjetivação, como afirmávamos anteriormente, visto ser o corpo o elemento que se inclui na heterogeneidade de elementos cuja relação se faz e se desfaz com o tempo. De fato, o campo semântico de subjetivar-se encampa noções, tais como conversão a si, um retorno no mesmo lugar, residir em si mesmo, onde está em jogo a idéia de todo um movimento da existência pelo qual se volta sobre si mesmo (Foucault, 1997, p. 123).

A idéia de remansos de um rio para descrever os processos de subjetivação evoca a famosa paisagem de Heráclito sobre o tempo, segundo a qual um homem não entra no mesmo rio duas vezes. Ora, um processo de subjetivação é quase o contrário disso. Para dar conta dessa configuração, pode-se arremedar a máxima de Heráclito que ficaria com a seguinte versão: um rio nunca passa pelo mesmo homem. No entanto, uma subjetivação não é exatamente o contrário da imagem heraclitiana, porque ela é um pequeno rio dentro do outro maior, mas é diversa, pois ela é um recesso, um lugar aonde as águas vêm descansar. Temos de ser cautelosos e não trocar o rio irrepetível e incansável por uma subjetivação sem parada. O rio maior tem uma capacidade de erosão, mas os remansos da subjetividade evidenciam uma potência de inclusão, isto é, um descanso em meio ao movimento. A subjetivação está aberta para o rio, mas igualmente oferece proteção contra a correnteza corrosiva. É o único lugar onde um sujeito, um $e$, uma identidade podem medrar.

E o corpo, o que tem a ver com a subjetividade? Essa foi uma lição em que Foucault insistiu particularmente.

\section{Subjetividade e corpo}

Tomando um atalho que vai facilitar nossa exposição, é bom dizer que corpo para Foucault não é sinônimo de organismo. O organismo é uma determinada disposição do corpo que visa adaptar uma potência de transformação ou de criação que também é corpo. Foucault denomina "prazer" esta potência que caracteriza o corpo pelo seu lado criativo ou transformacional; o prazer é a força do encontro que constitui o corpo das relações, como assinalávamos inicialmente, relações ou encontros de um corpo com as coisas, com outros corpos, idéias, imagens, etc. Tal potência pode ser observada, indiretamente, através dos mecanismos que visam sua captura. Foucault indica que esses aparelhos de captura funcionam principalmente no interior de morais cuja feição é jurídica, nestas a ênfase recai sobre

o código e ... sua capacidade de cobrir todos os comportamentos ..., a importância deve ser procurada do lado das instâncias de autoridade que 
fazem valer esse código, que o impõem à aprendizagem e à observação, que sancionam as infrações; nessas condições, a subjetivação se efetua, no essencial, de uma forma quase jurídica. (Foucault, 1984, p. 29)

Com efeito, a obra de Foucault pode ser entendida como um recenseamento desses mecanismos, nos quais o corpo transformacional ou criativo se delineia como uma linha de resistência ou de fuga à captura de sua potência. $\mathrm{O}$ alcance da noção foucaultiana de pražer evidencia-se na oposição que Foucault estabelece entre o corpo-prazer e o corpo-carne, onde o primeiro testemunha por forças de resistência da vida (Foucault, 1985a, p. 190). No fundo, é como se Foucault nos segredasse: - perceba essa violência, essa artimanha, essa crueldade meticulosamente urdida... bem, apesar disso, se pode ir adiante, algo resiste por nós.

Essa ambivalência entre o corpo capturado pelos mecanismos de poder e o corpo transformacional ou criativo pode ser historicamente observada, segundo Foucault, em uma outra linhagem de morais, estas não mais de caráter jurídico, visto que nelas o prazer não é mais tomado como uma energia natural a ser regrada, mas como uma potência que pode ser gerida e conservada. Nestas morais, diz Foucault, o elemento forte e dinâmico dever ser procurado nas formas de subjetivação e das práticas de si (Foucault, 1984, p. 30), de modo que o prazer seja entendido como uma estratégia circunstancial entre o corpo e os elementos que o envolvem (pp. 98-99).

Em termos gerais, estas últimas, as morais cuja ênfase se dá sobre as práticas que permitam transformar o próprio modo de ser (Foucault, 1984, p. 30) coincidem historicamente com a Antiguidade Greco-Romana (pagã), ao passo que as morais definidas pelo código correspondem ao Cristianismo. No entanto, alerta Foucault, entre elas howve justaposiçōes, por vezes rivalidades e conflitos, e por vezes composição (idem). Para sermos mais precisos, dentro de cada período histórico, o que permite separar o amálgama das duas linhagens da moral é a relação com a verdade, pois a questão das relações entre o uso dos pražeres e o acesso à verdade (Foucault, 1984, pp. 201-214) surge dentro da moral grega, mas dá o acesso a morais baseadas no código, como a cristã, quando o que passa a ser problematizado, afirma Foucault, não é mais o pražer, com a estética de seu uso, mas o desejo, com sua hermenêutica purificadora (p. 221). O uso dos prazeres se tornaria ainda mais austero, no dois primeiros séculos de nossa era, em função do aprofundamento acerca da relação do prazer com a verdade, a qual, enfim, torna as práticas de si associadas ao conbecimento de si, embora essas restrições ainda estejam muito distantes de uma moral prescritiva como a cristã (Foucault, 1985b, 1997).

A relação com a verdade, demonstra Foucault, vem acompanhada de uma certa acentuação dos efeitos nocivos do prazer, de modo que o corpo, ao invés de ser entendido como lugar onde o homem domina o prazer e por isso torna-se senhor de si, passa a ser visto como um espaço de fragilidade arrebatado por forças naturais cujo controle se deve mais a expedientes de proteção do que ao exercício de uma soberania sobre si mesmo (Foucault, 1985a). Sigamos por etapas afim de melhor esclarecer a relação do corpo com os modos de subjetivação e as práticas de si presentes em ambas a linhagens da moral, a saber, as de código e as baseadas na transformação do sujeito.
Numa moralidade característica Antiguidade Clássica, os prazeres do corpo são o domínio onde se constitui o autogoverno, perfazendo um campo contínuo onde não se demarca a questão do desejo; por exemplo, no campo dos prazeres não cabe a pergunta: em que tipo de relação há uma verdadeira reciprocidade do ponto de vista do amor, na relação heterossexual ou na relação homossexual? Já, numa Antiguidade Tardia, que corresponde à ascensão do Império Romano, a problematização do desejo, a qual vem acompanhada da indagação sobre o amor verdadeiro, de acordo com Foucault, desencadeará um processo que se estenderá à sexualidade, entendida como modo de subjetivação do sujeito moderno. O surgimento do desejo como novo modo de subjetivação atesta um

movimento que, na verdade, só se completará muito mais tarde, quando for edificada uma concepção absolutamente unitária de amor: a que separa as conjunções de um sexo ao outro e as relações internas a um mesmo sexo. É esse regime que, grosso modo, é ainda o nosso hoje em dia, na medida em que está solidificado por uma concepção unitária da sexualidade, que permite marcar de modo estrito o dimorfismo das relações, e a estrutura diferencial dos desejos. (Foucault, 1985a, p. 198)

O modo de subjetivação do sujeito moderno, que é, de certa forma, aquele que ainda experimentamos em nossos dias, não pode ser caracterizado como uma moral de código, no sentido prescritivo ou jurídico, que vigia em uma moral cristã. Foucault observa que, nas sociedades modernas, a relação do prazer com a verdade (scientia sexualis) orienta a subjetivação em torno de uma forma de poder-saber que instaura procedimentos voltados para que o indivíduo diga a verdade sobre o sexo (Foucault, 1985a, p. 57). O modo de subjetivação moderno, portanto, pode ser surpreendido em práticas de si reguladas por um dispositivo disciplinar, onde emerge a noção de sexualidade como constitutiva da subjetividade moderna. Sendo assim, a sexualidade, como modo de subjetivação, articula-se com a questão da relação entre o corpo-prazer (transformacional ou criativo) e a verdade sobre o sexo (Dreyfus \& Rabinow, 1984, 245).

Mas, de que forma historicamente específica, para que não se subentenda uma enganosa continuidade com a moral do desejo constituída nos dois primeiros séculos da era Cristã, a questão da verdade ainda reverbera no modo de subjetivação a que pertencemos? De que modo, enfim, a moderna relação da subjetividade com o corpo carrega ainda uma problematização antiga sem que, contudo, sua resolução seja a mesma?

Descrevamos, em síntese, por conseguinte, para responder a essa pergunta, o funcionamento da sexualidade no interior de uma sociedade disciplinar (Foucault, 1983). O dispositivo disciplinar de que fala Foucault caracteriza-se por espaços (a escola, a prisão, a fábrica, o hospital, o exército, o hospício, etc.) que confinam os corpos orgânicos dos indivíduos visando adestrá-los de alguma forma, mas o que o dispositivo disciplinar visa, de fato, é o corpo criativo (Dreyfus \& Rabinow, 1984; Foucault, 1983). Ele promove o corpo orgânico, mas a estratégia é tomar de assalto a potência transformacional do corpo, e torná-la disponível para cotizá-la entre várias funções. $\mathrm{O}$ caso da medicina da loucura já é conhecido: ela visa à cura da doença, ela é eficaz em aliviar ou entorpecer o corpo do louco, mas à custa de 
um controle da potência criativa desse corpo, controle este cuja história é mais longa e, portanto, mais antiga que a própria psiquiatria. Foucault demonstrou, justamente, que os bons momentos para se escrever uma história política do corpo, onde o dado a ser observado seria a vigência de mecanismos de poder cujo objeto é o corpo, seriam aquelas passagens históricas onde o corpo é disputado entre diferentes campos de saber, como se dá, por exemplo, na bifurcação entre o catolicismo e a medicina quanto ao fenômeno do corpo convulsionado (Foucault, 2001a).

O fato de que as estratégias de poder numa sociedade disciplinar procuram tornar disponível o corpo criativo revelase de modo evidente quando no interior do dispositivo disciplinar emerge um dispositivo de sexualidade, dispositivo este que, embora associado ao poder disciplinar, possui funções diversas. Por um lado, o dispositivo de sexualidade testemunha um fracasso relativo da disciplina, pois o adestramento dos corpos nos espaços disciplinares, a sua sujeição, não garante o controle sobre o corpo criativo. De certa forma, a potência dos corpos escapa aos dispositivos disciplinares, que se vêem perfurados, questionados e tornados ineficientes. Foucault mostra que o caráter dos espaços disciplinares é seu estado perene de crise, o que os faz tornar-se um laboratório de poder visando o aprimoramento contínuo de seus mecanismos (Foucault, 1983). Por outro lado, o surgimento do dispositivo de sexualidade, revela a busca, um tanto às cegas, pela suposta fonte da potência criativa dos corpos. Esse dispositivo, através de um elemento confessional, readaptado a uma nova função a partir da moral cristã da carne, procura estabelecer uma incitação técnica a falar da sexualidade, partindo do princípio de que aquele que pensa a sexualidade conhece melhor a si mesmo. Neste caso, novamente, vemos Foucault mostrar como a potência criativa dos corpos se esquiva - ou resiste - ao dispositivo de sexualidade (Dreyfus \& Rabinow, 247; Foucault, 1985a), na medida e que este procura estabelecer um certo eixo que gira em torno das relações entre comportamento sexual, a normalidade e a saúde (Foucault, 1984, p. 220).

Ora, o que sobra ou excede à sexualidade é que, sem dúvida, como supõe o dispositivo, o corpo é a fonte de nossa subjetividade, mas essa estratégia é insuficiente porque o dispositivo quer ancorar a subjetividade numa identidade cuja fixidez estaria modelada na história sexual do indivíduo. Mas a subjetividade está contida em um processo ou prática de subjetivação, e por isso não tem um mecanismo fixo; a subjetividade é diferenciação e não identidade.

Foucault ilustra fartamente a idéia de que o corpo resiste à sua disciplinarização, a sexualidade escapa dos mecanismos que procuram controlá-la e a subjetividade diferencia-se das estratégias identitárias que buscam focá-la. Há, entre outros exemplos, a tarefa impossível da medicina da sexualidade em classificar o espaço ocupado pela homossexualidade. De fato, o tratamento das perversões de ordem sexual deflagrou um furor classificatório com o fito de registrar as mínimas diferenças entre comportamentos sexuais, expediente este relativo à psiquiatrização doprazerperverso (Dreyfus \& Rabinow, 1984, 248; Foucault, 1985a). O resultado dessa cruzada taxionômica é que os comportamentos sexuais perversos pareciam ter uma variedade infinita, de modo que os critérios para sua classificação nunca eram bastante. Ora, esse relativo fracasso por parte da medicina da sexualidade indica, em primeiro lugar, que, de fato, a variedade é a regra em se tratando da sexualidade e, em segundo lugar, que o esforço do dispositivo de sexualidade se vê baldado porque todo controle deflagra uma resistência pela qual novos modos de comportamento sexual são criados à revelia do dispositivo.

Em vista disso, pode-se sintetizar, com certa fidelidade, a História da Sexualidade, principalmente em seu segundo e terceiro volumes, como uma trajetória pela qual a potência transformacional e criativa do corpo - o prazer - vai gradativamente sendo controlada por mecanismos que incidem sobre o corpo em sua relação com o tempo. O corpo, de um espaço onde se conquista o autogoverno (uso dos prazeres) acaba se tornando uma entidade frágil, que deve se precaver dos perigos iminentes ligados às forças naturais que $o$ constituem. O porto, a âncora, a relação que devolveria ao corpo sua calmaria quase impossível, portanto, estaria do lado da verdade, pela qual a subjetividade está em posição de vigia ou de contrapeso, em função da alegada mitigação do corpo, com relação aos modos de subjetivação e as práticas de si.

Em todo caso, a subjetividade é um processo que participa da potência de diferenciação do corpo, corpo ativo ou transformacional. Mas, o que significa dizer que a subjetividade tem a ver com o corpo, afinal, o que faz o corpo ter essa potência de transformação?

Ora, o corpo se transforma, a subjetividade se diferencia por causa da relação com o tempo. O corpo é coextensivo à subjetividade nos remansos do rio do tempo.

\section{Considerações Finais}

\section{Para que serve uma subjetividade hoje?}

Uma última questão, esta voltada para a atualidade da noção foucaultiana de subjetividade: o dispositivo de sexualidade ainda é estritamente válido?

A resposta é: não, não vale mais para a subjetivação contemporânea ou ele passa por uma crise tal que seus mecanismos estão definitivamente desfigurados e não funcionam como dantes. Essa constatação decorre de um problema que Foucault nos legou, isto é, os modos de subjetivação são demarcados por dispositivos historicamente constituídos e, portanto, podem se desfazer, transformando-se, à medida que novas práticas de subjetivação se engendram. É essa diluição histórica que parece estar deslocando o antigo dispositivo de sexualidade descrito por Foucault. Sendo assim, temos de pensar, para fazer jus e estender a lição foucaultiana, se não haveria em formação um novo dispositivo intermediando a relação da subjetividade com os processos de subjetivação, vale dizer, com o tempo e com o corpo. Vamos a um exemplo para ilustrar.

Em um artigo a respeito de Nietzsche, Orlandi (2001) demonstra de que maneira os processos de subjetivação abandonam a velha referência à identidade, caso que observamos um pouco acima como sendo o princípio de funcionamento dos dispositivos disciplinares e de sexualidade. Se tivermos ou quisermos uma identidade não temos mais de nela chafurdar, de mimá-la, de afirmá-la; se tivermos dúvida quanto à nossa verdadeira identidade, não temos de supô-la oculta 
em alguma parte, nem somos impelidos a partir em seu encalço numa busca angustiada. O sujeito agora se desfaz em uma série de processos que multiplicam as subjetividades que são mais ou menos montáveis e desmontáveis. Um neonarcisismo surge, anota Orlandi, onde a perigosa contemplação de si mesmo - a que praticava Narciso no espelho das águas - é substituída por uma série de exposições cujo controle parece fugir ao sujeito. O que vale é uma potência de variação que o sujeito sente como alheia e que somente pode ser acessada através de um aparelho - um novo dispositivo? - que intermedia a relação da subjetividade com a consciência que se tem dela. O sujeito já não sofre com a perda da identidade; ele até intensifica essa perda a fim de contabilizar mais rapidamente perdas e ganhos nas exposições do aparelho de intermediação. Enfim, cria-se uma espécie de narcisismo da diferença, onde o cuidado de si, como denominava Foucault, ou a potência de diferenciação do corpo, como dizemos nós, se vê capturada por um mecanismo que parece ter atingido o coração dos processos e práticas de subjetivação. De repente, estranhas potências passam a atravessar a relação do si consigo mesmo.

Ora, como se dizia um pouco acima, subjetividade é sinônimo de diferenciação, mas como fica o processo de subjetivação em uma época em que a produção da diferença foi capturada por um novo aparelho capaz de intermediar a relação de cada um de nós consigo mesmo?

Que tal questão fique como um elo de continuidade para investigações futuras.

\section{Referências}

Deleuze, G. (1986). Foucault. Paris: Minuit.

Diels, H. \& Kranz, W. (1951). Die fragmente der vorsokratiker, erster Band, secheste Auflag. Berlin: Weidmansche.

Dosse, F. (1994). História do estruturalismo (Vol. II). São Paulo: Ensaio.

Dreyfus, R. \& Rabinow, P. (1984). Michel Foucault: Um parcours philosophique. Paris: Gallimard.

Foucault, M. (1981). Aspalavras e as coisas: Uma arqueologia das ciências bumanas. São Paulo: Martins Fontes.

Foucault, M. (1982). Microfisica do poder: Rio de Janeiro: Graal.

Foucault, M. (1983). Vigiar e punir. Petrópolis, RJ: Vozes.

Foucault, M. (1984). História da sexualidade (Vol. II: O uso dos prazeres). Rio de Janeiro: Graal.

Foucault, M. (1985a). História da sexualidade (Vol. I: A vontade de saber). Rio de Janeiro: Graal.

Foucault, M. (1985b). História da sexualidade (Vol. III: O cuidado de si). Rio de Janeiro: Graal.

Foucault, M. (1994). Archivio Foucault (Vol. 3: Estetica dell'esistenza - A cura di Alessandro Pandofi). Milano: Feltrinelli.

Foucault, M. (1982). A bermenêutica do sujeito (Resumo dos Cursos do Collège de France) -1970-1982). Rio de Janeiro: Zahar.

Foucault, M. (1999). A água e a loucura. Rio de Janeiro: Forense.

Foucault, M. (2000). Arqueologia do saber. Rio de Janeiro: Forense.

Foucault, M. (2001a). Os anormais: Curso no College de France (1974-1975). São Paulo: Martins Fontes.

Foucault, Michel (2001b). L'herménentique du sujet, cours an College de France (19811982), édition établie sous la direction de François Ewald et Alessandro Fontana, par Frédéric Gross (Coll. Hautes Études). Paris: Gallimard/Seuil.

Orlandi, L. B. L. (2001). Marginando a leitura delenzeana do trágico em Nietżsche. (Manuscrito não-publicado).

Recebido: 18/03/2004

$1^{a}$ revisão: 19/05/2004

Aceite final: 20/08/2004

Sobre o autor

Hélio Rebello Cardoso Jr. é Historiador, Mestre e Doutor em Filosofia pela Universidade Estadual de Campinas. É livre-docente da Universidade Estadual Paulista, Campus Assis. 